\title{
Nonprescription Topical Treatments for Skin Rejuvenation
}

\author{
Lisa D. Grunebaum, MD ${ }^{1}$ Leslie S. Baumann, MD² \\ ${ }^{1}$ Division of Facial Plastic and Reconstructive Surgery, University of \\ Miami Miller School of Medicine, Miami, Florida \\ 2 Baumann Cosmetic and Research Institute, Miami, Florida
}

\begin{abstract}
Address for correspondence Lisa Grunebaum, MD, Division of Facial Plastic and Reconstructive Surgery, University of Miami Miller School of Medicine, Miami, FL 33136 (e-mail: Igrunebaum@med.miami.edu).
\end{abstract}

Facial Plast Surg 2014;30:3-11.
Abstract
Keywords
- aging
- skin rejuvenation
- topical treatments

Topical skin care regimens are a mainstay treatment for aging skin. All patients seeking skin rejuvenation can benefit from this low-risk intervention. This article reviews available nonprescription topical treatments for rejuvenation including moisturizers, antioxidants, retinols, and sunscreen.
This article aims to review available over-the-counter (OTC) topical treatments for specific findings related to aging skin. Rejuvenation by topical methods is a widely available and low-risk aspect of antiaging regimens. The authors recommend that all patients seeking skin rejuvenation be placed on an individualized regimen discussed during in-office consultation. Patient complaints, such as dryness/sensitivity and wrinkles, should be specifically discussed and addressed. We have found the Baumann Skin Typing system to be of great use in this area. Specifics on using this questionnaire are outside the realm of this article but may be found at www.skintypesolutions.com/home. This article will focus on selected topical antiaging facial cosmetic ingredients based on dry, sensitive, and wrinkled presentations. An antiaging regimen is likely to include prescription topicals such as a vitamin A derivative or antipigment agent and these topicals will be discussed in separate articles in this issue entitled, "Topicals for Skin Rejuvenation: Prescription Topicals" and "Treatment of Unwanted Pigment."

Cutaneous aging results from the complex interaction of intrinsic and extrinsic factors. Intrinsic aging is based on individual heredity and the natural effects of the passage of time. Extrinsic aging occurs from exogenous insults and manifests in premature skin aging, especially in the face. Rhytid formation, engendered by changes in the dermal layer of skin, is the primary manifestation of skin aging. Importantly, despite numerous false claims by manufacturers to the contrary, few skin care products are proven to adequately penetrate the dermis to improve deep wrinkles. Therefore, preventing rhytids is the goal of dermatologic antiaging skin care. ${ }^{1}$ Unwrinkled skin is the skin that has been largely protected from exogenous aging factors.

Dry skin is a also a hallmark of aging, as older skin is impacted by declining production of sex hormones and collagen, manifesting in skin with decreased thickness, increased wrinkling and a much greater tendency toward dryness. ${ }^{2-4}$ Dry skin is characterized by an impaired barrier, lack of natural moisturizing factor (NMF), and/or reduced sebum production, whereas oily skin is characterized by increased sebum production. Aging skin can also present as sensitive and even friable and some patients may manifest aging skin in this way. While sensitive skin is characterized by inflammation and presents as acne, rosacea, burning and stinging sensations, or skin rashes, resistant skin is typified by a strong stratum corneum (SC) that imparts cutaneous protection from allergens, other environmental factors, and water loss. While resistant skin is less prone to acne, it is also less amenable to topical therapy, thus requiring stronger skin care products and in-office procedures as compared with sensitive skin.

\section{Dry Skin}

\section{Basic Skin Care Formulations}

Dry skin can be treated by augmenting SC hydration with occlusive or humectant ingredients and smoothing rough surfaces with an emollient. Occlusives coat the SC and slow transepidermal water loss (TEWL); humectants attract water
Issue Theme Classical and State-of-theArt Skin Rejuvenation; Guest Editors, Lisa D. Grunebaum, MD, and Noëlle S. Sherber, MD, FAAD
Copyright (c) 2014 by Thieme Medical Publishers, Inc., 333 Seventh Avenue, New York, NY 10001, USA. Tel: +1(212) 584-4662.
DOI http://dx.doi.org/ 10.1055/s-0033-1363755. ISSN 0736-6825. 
from the atmosphere and the epidermis; emollients soften and smooth the skin. Surface acting ingredients, or surfactants, are the primary active ingredients in cleansers, which are used more often than any other skin care products. Cleansing products include bar surfactants, superfatted soaps, transparent soaps, combination bars, synthetic detergent bars, and liquid surfactants. Patients with dry skin should use nonfoaming agents, such as a cleansing milk, oil, or cream.

\section{Moisturizers}

Moisturizers increase water content in the SC by blocking TEWL through occlusive ingredients or by enhancing the integrity of the skin barrier, which is achieved via delivery of fatty acids, ceramides, and cholesterol to the skin and controlling the calcium gradient. Moisturization is also achieved by augmenting levels of NMF, glycerol (glycerin), and other humectants (e.g., hyaluronic acid). In addition, skin hydration is improved by enhancing epidermal capacity to absorb important circulatory components, such as glycerol and water, through aquaporin channels. Most moisturizers, which are designed to improve skin hydration, are oil-inwater emulsions (e.g., creams and lotions) or water-in-oil emulsions (e.g., hand creams).

\section{Occlusives}

Widely used in skin care cosmetics, occlusives are oily substances that can dissolve fats and coat the SC to inhibit TEWL, resulting in an emollient effect. Petrolatum and mineral oil are among the most effective occlusive agents. A purified mixture of hydrocarbons derived from petroleum (crude oil) and used as a skin care product since 1872, petrolatum, the gold standard of occlusives, displays a water vapor loss resistance 170 times that of olive oil. ${ }^{5}$ The hydrocarbon molecules present in petrolatum prevent oxidation, giving it a long shelf life. ${ }^{6}$ However, petrolatum has a greasy texture that many patients find unappealing. Cosmetic grade mineral oil, a noncomedogenic agent derived from the distillation of petroleum in gasoline production, has been available for over a century and is one of the more commonly used oils in skin products. ${ }^{7}$ It is important to note that occlusives are effective only while on the skin; TEWL returns to previous levels when the agent is removed. In moisturizers, occlusives are often combined with humectants. Lanolin, paraffin, squalene, dimethicone, propylene glycol, beeswax, soybean oil, grapeseed oil, ${ }^{8}$ and other "natural" oils (e.g., sunflower seed, evening primrose, olive oil, and jojoba oils) are also among the commonly used occlusive ingredients. ${ }^{9-13}$ Linoleic acid, an omega-6 fatty acid present in sunflower, safflower, and other oils, is an essential fatty acid obtained from the diet or through topical application that is necessary for the production of ceramide in the skin barrier.

\section{Humectants}

Humectants are water-soluble substances with high water absorption capacity. These compounds can attract water from the deeper epidermis and dermis in low-humidity conditions, which can exacerbate dry skin. ${ }^{10}$ Therefore, manufacturers combine humectants with occlusive ingredients to achieve the desired effect. In cosmetic moisturizers, humectant ingredients protect against evaporation and thickening of the product, thus extending the shelf life. Humectants can also change skin appearance by drawing water into the skin, causing mild SC swelling that makes the skin look smoother and less wrinkled. Manufacturers often capitalize on this phenomenon by touting some moisturizers as "antiwrinkle creams" even though no long-term antiwrinkling effects are delivered. Glycerin, urea, sorbitol, sodium hyaluronate, propylene glycol, $\alpha$-hydroxy acids, and sugars are among the commonly used humectant ingredients. Glycerin (glycerol) is a potent humectant with hygroscopic capacity comparable to NMF, ${ }^{11}$ allowing the SC to retain a significant amount of water even in a dry environment. Urea, included in hand creams since the $1940 \mathrm{~s},{ }^{12}$ is a constituent of the NMF and displays mild antipruritic activity. ${ }^{13}$

\section{Emollients}

Emollients render a smooth appearance by filling the spaces between desquamating corneocytes and increasing cohesion, resulting in a flattening of the curled edges of the individual corneocytes. In addition, several emollients exhibit humectant and occlusive qualities. Occlusives that also confer an emollient effect include lanolin, mineral oil, and petrolatum. Several natural ingredients also impart such benefits and include oatmeal, shea butter, vitamins $\mathrm{C}$ and $\mathrm{E}$, coffeeberry, green tea, coenzyme $\mathrm{Q}_{10}\left(\mathrm{CoQ}_{10}\right)$, niacinamide, soy, and glycyl-L-histidyl-L-lysine- $\mathrm{Cu}^{2+}$ (GHK-Cu), a copper tripeptide complex used for many years to enhance wound healing and more recently shown to augment collagen production. ${ }^{14,15}$

Ideal moisturizers contain humectant as well as occlusive ingredients. Glycerin is one of the better humectants because it can cross aquaporin channels and penetrate into the dermis. The best occlusive ingredients are oils that contain antioxidants and/or linoleic acid, including safflower oil, sunflower oil, olive oil, walnut oil, peanut oil, and grape seed oil.

\section{Hydroxy Acids}

Alpha-hydroxyl acids (AHAs), a group of water-soluble, naturally occurring compounds with a hydroxy group in the $\alpha$ position, function as humectants and exfoliants. Lactic acid (derived from sour milk), glycolic acid (from sugarcane), citric acid (from citrus fruits), malic acid (from apples), tartaric acid (from grapes), and phytic acid (from rice) are members of this versatile family of compounds. ${ }^{16}$ Lactic and glycolic acids were the first AHAs to reach the market and remain the most commonly used AHAs. For over 35 years, topical formulations using AHAs have been known to influence epidermal keratinization. ${ }^{17}$ It is important to note that preparations containing AHAs are required by the U.S. Food and Drug Administration (FDA) to include a label warning that sun protection should accompany product use.

\section{Lactic Acid}

First used in 1943 to treat ichthyosis, ${ }^{18}$ lactic acid is a popular AHA present in several at-home products and prescription 
moisturizers. Lactic acid is the only AHA that is also a component of the NMF, which, as suggested above, plays an important role in skin hydration. Notably, the application of the L-isomer of lactic acid to keratinocytes increases the ratio of ceramide 1 linoleate to ceramide 1 oleate, which is significant insofar as a lower ceramide 1 linoleate to ceramide 1 oleate ratio is associated with atopic dermatitis and acne. ${ }^{19,20}$ Lactic acid also confers antiaging effects, as suggested by a double blind vehicle-controlled study in which an $8 \%$ L-lactic acid formula performed better than vehicle in treating photoaged skin, with statistically significant amelioration of skin roughness, mottled hyperpigmentation, and sallowness. ${ }^{21}$

\section{Sensitive Skin}

Sensitive skin has defied easy characterization. Two classification systems have been proffered in the last decade, but a definitive typing system for sensitive skin remains elusive. $^{22,23}$ Individuals can suffer from combinations of sensitive skin subtypes. The following discussion focuses on the primary topical treatments for sensitive skin.

\section{Topical Treatments for Sensitive Skin}

\section{Salicylic Acid}

In experimental as well as clinical settings, salicylates have demonstrated anti-inflammatory and antimicrobial activity. ${ }^{24}$ Salicylic acid, a member of the aspirin family, interrupts the arachidonic acid cascade, thus exerting analgesic and anti-inflammatory effects. Salicylates control inflammation by inhibiting proinflammatory gene expression. Salicylic acid decreases the frequency and severity of acne eruptions by mitigating acne-related inflammation while delivering exfoliating activity to the pores. Because it is lipophilic, it is more able than glycolic acid to penetrate the sebum in skin pores, which accounts for its popularity in OTC acne products. Salicylic acid $2 \%$ cleansers are effective treatment options for rosacea patients with oily skin.

\section{Sulfur/Sulfacetamide}

Sulfur, usually an adjuvant therapy, is used primarily to treat acne, seborrheic dermatitis, rosacea, scabies, and tinea versicolor. ${ }^{25}$ Elemental sulfur and its various forms (e.g., sulfides, sulfites, and mercaptans) act as anti-inflammatory agents and reportedly display antifungal, antimicrobial, and antiparasitic activity. ${ }^{26}$ Sulfur is often combined with sodium sulfacetamide, a sulfonamide agent with antibacterial properties, specifically acting as a competitive antagonist to para-aminobenzoic acid, an essential component for bacterial growth, ${ }^{27}$ and Propionibacterium acnes. ${ }^{28}$ The combined keratolytic and anti-inflammatory activity of sulfur and the antibacterial properties of sulfacetamide in a topical formulation render an effective treatment for acne vulgaris, rosacea, and seborrheic dermatitis. ${ }^{29}$ Sulfur is combined with sodium sulfacetamide in cream, lotion, gel topical suspension, cleanser, and silica-based mask preparations. However, the odor of many of these products has been likened to rotten eggs, limiting their popularity.

\section{Natural Ingredients}

In the past 20 years, botanically derived products have gained widespread interest and use in the US. ${ }^{30}$ Indeed, many such ingredients have been shown in recent years to impart antiinflammatory activity, including aloe vera, ${ }^{31,32}$ chamomile, $^{33}$ feverfew, ${ }^{34,35}$ ginseng, ${ }^{36,37}$ licorice extract, ${ }^{38,39}$ mushrooms, ${ }^{40,41}$ oatmeal, ${ }^{42,43}$ selenium, ${ }^{44,45}$ and turmeric. ${ }^{46,47}$

\section{Wrinkled Skin}

Wrinkled skin is more readily prevented than successfully treated. Well-known effective behaviors to avert photoaging include the use of broad-spectrum sunscreen (blocking UV-A and UV-B) and sun avoidance during the peak hours of $10 \mathrm{Am}$ to 4 PM. A routine skin care regimen that entails topical retinoid application may also aid in the prevention and treatment of cutaneous aging. Topical retinoids foster collagen synthesis and thwart the matrix metalloproteinases (MMPs) active in collagen and elastin degradation. ${ }^{48,49}$ It is also important in the dermatologic arsenal against wrinkling are antioxidants, which countervail the oxidative stress and free radicals created by UV irradiation.

\section{Retinoids}

For many years, retinoids, a family of compounds derived from vitamin A, have been used topically and systemically to treat dermatologic disorders, especially acne. Indeed, more than 25 years ago, female acne patients reported smoother skin and fewer wrinkles after treatment. ${ }^{50}$ This led to a clinical trial showing that patients treated with tretinoin experienced improvement in sunlight-induced epidermal atrophy, dysplasia, keratosis, and dyspigmentation. ${ }^{51}$ Additional findings from several clinical trials led to FDA approval of tretinoin (Renova; Ortho Pharmaceutical Corporation, Raritan, NJ) to treat photodamage. Renova, Avage (Allergan, Irvine, CA), and Refissa (Spear Dermatology Products, Randolph, NJ) are the only topical agents approved for this purpose.

Significantly, tretinoin may also play a role in the prevention of cutaneous aging. UV-B exposure upregulates the development of multiple MMPs, and the activation of MMP genes promotes the production of collagenase, gelatinase, and stromelysin, which fully degrade the skin collagen. ${ }^{52}$ However, the induction of these MMPs has been shown to be inhibited by tretinoin application. ${ }^{49}$ Collagen synthesis has also been demonstrated to be diminished due to UV exposure. Cutaneous pretreatment with tretinoin has been shown to suppress UV induction of MMPs; therefore, consistently pretreating the skin with topical retinoids appears to have the potential to prevent as well as treat photodamage. ${ }^{53}$ Collagen synthesis in photoaged human skin has also been promoted by the use of retinoids. ${ }^{48}$ Specifically, levels of collagen type I have been partially restored by the topical application of tretinoin $0.1 \%$ to photodamaged skin. The metabolic precursor of tretinoin, retinol, is a key ingredient found in various OTC cosmetic products advertised as "antiwrinkle" creams. ${ }^{54}$

Though they bear little structural resemblance to retinol, the newest retinoids impart biological action via the same 
nuclear receptors modulated by the active natural metabolite of vitamin A, retinoic acid. Third-generation retinoids, of which there are now over 2,500 products, ${ }^{55}$ are more photostable than the first- and second-generation formulations. ${ }^{56}$ However, a report by the Environmental Working Group has stirred controversy about one retinoid, retinyl palmitate, suggesting that it may promote skin cancer development. ${ }^{57}$ The American Academy of Dermatology denies that there is any such evidence. ${ }^{58}$ What we do know is that retinyl palmitate delivers some sunscreen effects by absorbing UV$\mathrm{B}$, but it may also absorb UV-A and act as a photosensitizer. While it is undetermined whether retinyl palmitate actually imparts a carcinogenic effect, it has been established that retinol penetrates human skin more effectively than retinyl palmitate. ${ }^{58,59}$ In addition, several retinoids have been shown to exert anticarcinogenic effects. Based on the superior efficacy, the authors recommend retinol or tretinoin products, not retinyl palmitate.

Retinol, a prodrug that can be converted to retinoic acid by the skin, is highly effective in skin care. The change to all-trans retinoic acid within the keratinocytes is essential for retinol to be active. ${ }^{60}$ Upon exposure to light, retinol degrades into a biologically inactive molecule. This breakdown can be prevented by adding an antioxidant or by incorporating retinol into an oxidation-resistant vehicle. Recent investigations of retinol in an appropriate vehicle and in the correct concentration have shown it to be as effective as tretinoin for the same indications. In one study, unoccluded retinol at $0.25 \%$ was found to induce the same cellular and molecular changes observed with the application of $0.025 \%$ tretinoin-without the irritation usually seen with tretinoin. In addition, the investigators found that retinol penetrated the skin better than tretinoin. ${ }^{59}$ Side effects from retinol are also less frequent than with tretinoin; therefore, retinol may be an excellent alternative for patients with sensitive skin. In addition, vitamin $A$ is also known to be a humectant moisturizer and therefore is a useful additive in products meant to moisturize the skin. ${ }^{61}$

\section{Antioxidants}

Several antioxidants have demonstrated significant capacity to exert photoprotective effects. While a suitable discussion of this subject is beyond the scope of this article, it is worth noting that the list of antioxidants or antioxidant-containing compounds associated with such effects includes but is not limited to vitamins $\mathrm{C}^{62,63}$ and $\mathrm{E},{ }^{64} \mathrm{CoQ}_{10},{ }^{65}$ grape seed extract, ${ }^{66,67}$ resveratrol, ${ }^{68,69}$ green tea, ${ }^{70,71}$ lycopene, ${ }^{72}$ feverfew, ${ }^{31}$ turmeric, ${ }^{73}$ idebenone, ${ }^{74}$ and coffeeberry. ${ }^{74}$ This discussion will be limited to brief reviews of antioxidant theory as well as the antioxidants $\mathrm{CoQ}_{10}$, green tea, resveratrol, and vitamins $\mathrm{C}$ and $\mathrm{E}$.

\section{Antioxidant Theory}

The free radical theory of aging, first hypothesized in 1956, is now the most widely accepted theory to account for the etiology of cutaneous aging. ${ }^{75,76}$ Reactive oxygen species, also known as free radicals, are chemically reactive molecules containing oxygen. Stable oxygen has an even number of electrons. When something consumes or removes one of the electrons from oxygen (such as UV exposure), oxygen is left with an unpaired electron that renders it reactive. These inherently unstable, and thus harmful, free radicals steal electrons from other cellular components to regain an even number of electrons. Free radicals can take electrons from DNA, lipids in cell membranes (such as low-density lipoproteins, also known as the "bad cholesterol"), proteins, and other vital structures, leaving them impaired. Free radicals can be generated by UV exposure, cigarette smoking, normal cellular processes such as oxidative phosphorylation, as well as sunscreens and other chemicals upon decomposition. Skin aging is thought to result from DNA damage, lipid peroxidation, and inflammation provoked by free radicals. Antioxidants provide free radicals with the electrons they lack, thus neutralizing them or rendering them innocuous.

\section{Coenzyme $\mathrm{Q}_{10}$}

$\mathrm{CoQ}_{10}$, also known as ubiquinone (as it is a member of the quinone family), is a fat-soluble compound found in all cells. It contributes to the electron transfer chain responsible for energy production and is believed to account for $95 \%$ of the body's ATP or energy needs. ${ }^{77}$ In addition to its natural presence in human cells, $\mathrm{CoQ}_{10}$ is abundant in fish and shellfish. Topical $\mathrm{CoQ}_{10}$ has been shown to penetrate into the viable layers of the skin and significantly suppress collagenase expression in human dermal fibroblasts after UV-A exposure. ${ }^{65}$ In addition, extended supplementation of $\mathrm{CoQ}_{10}$ in humans has been demonstrated to reduce periocular wrinkle formation. $\mathrm{CoQ}_{10}$ is stable in topical products but the long-term capacity of such products to prevent or retard cutaneous aging has not been established. Recent in vivo studies have revealed the lessening of photoaging symptoms as a result of the topical application of $\mathrm{CoQ}_{10}$, though the bioavailability of $\mathrm{CoQ}_{10}$ has remained poor. ${ }^{78}$

\section{Green Tea}

Green tea, the globally popular beverage, has been the subject of scrutiny in recent years for its purported antioxidant and anticarcinogenic activity. In fact, green tea is one of the most researched of the antioxidants, with numerous studies on its cutaneous effects. ${ }^{79}$ Among the key constituents of green tea are four major polyphenolic catechins: ECG [(-)EpiCatechin3-O-Gallate], GCG [(-)GalloCatechin-3-O-Gallate], EGC [(-) EpiGalloCatechin], and EGCG [(-)EpiGalloCatechin-3-O-Gallate], the most abundant and biologically active component. Early studies revealed that orally administered or topically applied green tea polyphenols blocked chemical- and UVinduced carcinogenesis in hairless or Sencar mice. ${ }^{80-82}$ In subsequent work that has confirmed and elaborated on such results, EGCG has emerged as a potent photocarcinogenesis inhibitor. ${ }^{83}$ In human skin, topically applied green tea polyphenols have been shown to dose-dependently diminish UVinduced erythema and sunburn cell formation, limit DNA damage, and protect epidermal Langerhans cells. ${ }^{84}$ Topically applying green tea polyphenols in the morning in combination with sunscreens is thought to potentially enhance skin protection against UV damage. That said, the body of evidence 
on the effects on human skin of topically applied green tea polyphenols remains relatively small, despite copious research. $^{85}$

\section{Resveratrol}

Resveratrol (trans-3,5,4'-trihydroxystilbene), a polyphenol found in the skin and seeds of grapes, berries, peanuts, red wine, and other foods, exhibits a wide range of biological and pharmacological activity, ${ }^{86}$ including strong antioxidant, antiproliferative, and anti-inflammatory characteristics. ${ }^{69,87}$ Notably, resveratrol has been demonstrated, in vitro and in vivo, to impart chemopreventive and antiproliferative activity against various cancers, including skin cancer, by inhibiting cellular events linked to tumor initiation, promotion, and progression and inducing apoptosis in such tumor cells. ${ }^{8-90}$ Recent studies support the notion of this antioxidant conferring a photoprotective effect against UV radiation. ${ }^{91,92}$

\section{Vitamin C}

Most evidence supporting beneficial, including antioxidant, effects of vitamin $C$ (ascorbic acid) are derived from investigations of oral vitamin $\mathrm{C}$ or vitamin $\mathrm{C}$ applied to tissue cultures. There are no studies indicating that oral vitamin $C$ consumption increases cutaneous vitamin $C$ levels. Manufacturers have exploited this lack of knowledge by producing and touting topical vitamin $\mathrm{C}$ preparations, many of which have become popular. A lipid form of vitamin C, topical ascorbyl palmitate, is nonirritating and reportedly exerts photoprotective and anti-inflammatory activity. ${ }^{93}$ Because few of the currently available topical vitamin $C$ formulations can penetrate the SC, most such products are useless. Nevertheless, several studies reveal that mice treated with topical vitamin C exhibited less erythema, fewer sunburn cells, and decreased tumor formation in treated skin after UV exposure. ${ }^{94}$ As a topical agent, vitamin $C$ has been used to capitalize on its antioxidant activity to prevent photodamage, and to treat melasma, striae albae, and postoperative erythema in laser patients. ${ }^{95-97}$

\section{Vitamin E}

Vitamin $\mathrm{E}$ (tocopherol), such as $\mathrm{CoQ}_{10}$, is found in the lipophilic portion of the cell membrane. The nutrient naturally occurs in vegetables, oils, seeds, nuts, corn, soy, whole wheat flour, margarine, and in some meat and dairy products, and is the main fat-soluble antioxidant in skin that protects cells from oxidative stress. ${ }^{98}$ The public and some doctors use it to treat minor burns, surgical scars, and other wounds, even though its use for dermatoses has not been approved by the FDA. The authors do not ever recommend the use of vitamin $\mathrm{E}$ in scar treatment and feel that it may even exacerbate scar healing and ultimately detract from appearance. ${ }^{99}$ But the use of vitamin E is believed to lessen the degree of lipid peroxidation and protect against cardiovascular disease. ${ }^{100}$ Vitamin E likewise protects cutaneous cell membranes from peroxidation.

\section{Sunscreens}

Sun exposure deposits UV radiation into the skin and is known to not only cause skin cancer but contribute to the appearance of aged skin, wrinkles, and uneven skin tone due to mottled pigmentation. UV radiation is made up of $96.5 \%$ UV-A and 3.5\% UV-B on an average summer day. UV-B is more likely to cause squamous cell carcinoma and can be blocked by glass, while UV-A is believed to be a cause of melanoma and can penetrate glass. UV-A can also penetrate deep into the skin and cause wrinkles. There are many different sunscreens available, all with varying sun protection factor (SPF) displayed on the label. SPF numbers refer only to the amount of protection against UV-B and not UV-A, meaning that sunscreen SPF does not reveal how well the particular sunscreen guards against UV-A absorption.

There are two types of sunscreens: physical blockers and chemical blockers. Physical blockers, otherwise known as "barrier sunscreens," reflect UV radiation. Because there is no systemic absorption, physical blockers (e.g., titanium dioxide, zinc oxide, and magnesium oxide) rarely cause an allergic reaction. Chemical blockers (e.g., avobenzone) are usually combined with physical blockers for periods of increased sun exposure. Chemical sunscreens absorb the UV radiation, and the chemicals in sunscreens are systemically absorbed. Therefore, there is a risk of allergic reactions with chemical blockers, and they are contraindicated in small children. The authors endorse a regimen that begins first with an antioxidant product layer followed by an antioxidantcontaining sunscreen, or two different types of broad-spectrum sunscreens. The best products include avobenzone (now in a stable form known as Helioplex [Neutrogena, Los Angeles, CA]), Mexoryl (L'Oréal, New York, NY)-containing formulations, and the physical blockers zinc oxide and titanium dioxide.

As previously described, some antioxidants have photoprotective properties. Although they should not be used as a substitute for sunscreen, they can be combined with sunscreen use. One recent study addressed the question of antioxidants and sun exposure. Yuan et al found that topical grape seed proanthocyanidin extract applied before sun exposure protected against UV-induced damage and mutant p53 epidermal cell formation. ${ }^{101}$

Although the FDA has been moving toward improved standardized sunscreen labeling including SPF standards as well as decreased tolerance for "waterproof" claims, recommendations have not been finalized. One of the most important changes for consumers includes stricter labeling for "broad spectrum." A sunscreen labeled in this way must show efficacy against both UV-A and UV-B radiation, helping to prevent both skin cancer as well as sunburn. The authors recommend a daily SPF of at least 30 for daily use and 50 for prolonged outdoor use. We also do not feel that the SPF contained in most makeup is sufficient. Repeated and sufficient application is also more effective (every 2 hours or after water exposure). A commonly quoted acceptable amount of applied sunscreen for protection is "one ounce or enough to fill a shot glass" over sun-exposed areas. ${ }^{102}$

\section{Peptides}

Composed of chains of amino acids and derived from DNA transcription, peptides have recently been incorporated as 
biologically active compounds in antiaging cosmeceutical products. Peptides communicate between DNA and the cellular network and are therefore believed to be instrumental in directing cells to maintain a stable, nonaging manifestation. In particular, peptides have been credited with downregulating MMPs, especially collagenase, thus suggesting a role in antiaging applications. ${ }^{103,104}$ The total surface of wrinkles in addition to the number and average depth of wrinkles was significantly decreased in a double-blind clinical study in 2004 of 20 healthy women between 40 and 62 years of age after the topical application of a gel formula containing $3 \%$ of a collagen-like hexapeptide. ${ }^{105}$ In a literature review in 2005 , Lupo found that peptide cosmeceuticals display the potential to diminish cutaneous aging when the formulations are stable, absorbed into the skin, and biologically active. ${ }^{106}$ Peptides used in cosmeceuticals fall under four categories.

\section{Signal Peptides}

In vitro and in vivo studies have shown that the valine-glycinealanine-proline-glycine peptide, the tyrosine-tyrosine-arginine-alanine-aspartame-aspartame-alanine peptide, and the lysine-threonine-threonine-lysine-serine peptide foster human skin dermal fibroblast growth, and decrease the length and depth of wrinkles. ${ }^{107}$ The latter peptide, the most popular signal peptide, has been linked to palmitic acid in a marketed product (Matrixyl [Sederma, Inc., Edison, NJ]) that has been demonstrated to increase the production of collagen by fibroblasts, ${ }^{108}$ and reduce fine lines and wrinkles. ${ }^{109}$ Signal peptides promote the synthesis of key dermal constituents, particularly collagen but also elastin and glycosaminoglycans, thus contributing to younger looking skin. ${ }^{110}$

\section{Enzyme-Inhibitor Peptides}

Found in antiaging, moisturizing, cleansing, and hair products, ${ }^{111,112}$ these peptides directly or indirectly block enzymatic activity. In 2007, a rice peptide derived from germinated black rice was noted for inhibiting MMP activity and dose-dependently stimulating hyaluronan synthase 2 gene expression in human keratinocytes. ${ }^{113}$ Sericin, an enzyme-inhibiting peptide produced in the Moddle silk gland of the silkworm Bombyx mori, has been demonstrated to hinder tyrosinase activity and keratinocyte apoptosis and to aid skin moisturization by restoring amino acids and conferring an occlusive effect. ${ }^{114,115}$

\section{Neuropeptides}

Neuropeptides, also known as neurotransmitter-affecting peptides, mediate skin inflammation and are included in cosmeceuticals to mimic the action of botulinum toxin A by suppressing acetylcholine release at the neuromuscular junction. ${ }^{116,117}$ Marketed as Argireline (Lipotec, LLC, Barcelona, Spain), acetyl hexapeptide-3 (AC-gly glu-met-gln-arg-arg$\mathrm{NH} 2$ ) is a synthetic peptide based on the $\mathrm{N}$-terminal end of the synaptosome-associated protein-25 that inhibits soluble N-ethyl-maleimide-sensitive factor attachment protein receptor complex development and catecholamine release. ${ }^{118,119}$ It is thought to limit the release of neurotransmitters, thus reducing facial tension and wrinkles. Most data on this form of peptide come from proprietary studies. Much more evidence is needed to determine the efficacy of these peptides as topical antiaging agents.

\section{Carrier Peptides}

Carrier peptides stabilize and transport trace elements necessary for wound healing and enzymatic processes. ${ }^{120}$ Glycyl-Lhistadyl-L-lysine (GHK), a naturally occurring tripeptide first isolated from human plasma, ${ }^{121}$ which acts as both a carrier and signal peptide is often coupled with copper, due to its high affinity for the element. Copper peptide molecules using GHK (GHK-Cu) have been shown to ameliorate the appearance of fine lines and wrinkles. ${ }^{122} \mathrm{GHK}-\mathrm{Cu}$, in use for several years to speed wound healing and as an ingredient in moisturizers, has been demonstrated to spur collagen production and to affect tissue remodeling by increasing the levels of MMP-2 tissue inhibitors of MMPs (TIMP-1 and TIMP-2). ${ }^{123-125}$ More research is needed to establish the effectiveness of these intriguing products. At this time, signal and enzyme-inhibitor peptides appear to have larger roles to play as antiaging agents.

\section{Conclusion}

To achieve optimal results for patients, whether they are to rejuvenate their skin through topical therapy alone or having surgery or receiving dermal fillers, botulinum toxin injections, or laser treatments, it is important to recommend the proper skin care regimen, starting with topical products. To improve the likelihood of patient compliance, the skin care regimen should be reviewed at each patient visit. Retinoids, antioxidants, and sunscreens are the mainstay of a good antiaging skin care regimen. Prescription topical treatments are reviewed in subsequent and separate articles in this issue entitled, "Topicals for Skin Rejuvenation: Prescription Topicals" and "Treatment for Unwanted Pigment."

\section{References}

1 Baumann L. How to prevent photoaging? J Invest Dermatol 2005; 125(4):xii-xiii

2 Genazzani AD, Lanzoni C, Genazzani AR. Might DHEA be considered a beneficial replacement therapy in the elderly? Drugs Aging 2007;24(3):173-185

3 Borg M, Brincat S, Camilleri G, Schembri-Wismayer P, Brincat M, Calleja-Agius J. The role of cytokines in skin aging. Climacteric 2013;16(5):514-521

4 Calleja-Agius J, Muscat-Baron Y, Brincat MP. Skin ageing. Menopause Int 2007;13(2):60-64

5 Spruit D. The interference of some substances with the water vapour loss of human skin. Dermatologica 1971;142(2):89-92

6 Morrison D. Petrolatum. In: Loden M, Maibach H, eds. Dry Skin and Moisturizers. Boca Raton: CRC Press; 2000:251

7 DiNardo JC. Is mineral oil comedogenic? J Cosmet Dermatol 2005; $4(1): 2-3$

8 Draelos Z. Moisturizers. In: Draelos Z, ed. Atlas of Cosmetic Dermatology. New York, NY: Churchill Livingstone; 2000:83

9 Darmstadt GL, Mao-Qiang M, Chi E, et al. Impact of topical oils on the skin barrier: possible implications for neonatal health in developing countries. Acta Paediatr 2002;91(5):546-554

10 Idson B. Dry skin: moisturizing and emolliency. Cosmet Toilet 1992;107:69-78 
11 Chernosky ME. Clinical aspects of dry skin. J Soc Cosmet Chem 1976;27:365-376

12 Harding C, Bartolone J, Rawlings A. Effects of natural moisturizing factor and lactic acid isomers on skin function. In: Loden $\mathrm{M}$, Maibach H, eds. Dry Skin and Moisturizers. Boca Raton: CRC Press; 2000:236

13 Kligman AM. Dermatologic uses of urea. Acta Derm Venereol 1957;37(2):155-159

14 Maquart FX, Pickart L, Laurent M, Gillery P, Monboisse JC, Borel JP. Stimulation of collagen synthesis in fibroblast cultures by the tripeptide-copper complex glycyl-L-histidyl-L-lysine-Cu2+. FEBS Lett 1988;238(2):343-346

15 Maquart FX, Bellon G, Chaqour B, et al. In vivo stimulation of connective tissue accumulation by the tripeptide-copper complex glycyl-L-histidyl-L-lysine-Cu2+ in rat experimental wounds. J Clin Invest 1993;92(5):2368-2376

16 Lawrence N, Brody HJ, Alt TH. Chemical peeling. In: Coleman W, Hanke W, eds. Cosmetic Surgery of the Skin,. 2nd ed. St. Louis: CV Mosby; 1997:85-111

17 Van Scott EJ, Yu RJ. Control of keratinization with alpha-hydroxy acids and related compounds. I. Topical treatment of ichthyotic disorders. Arch Dermatol 1974;110(4):586-590

18 Stern EC. Topical application of lactic acid in the treatment and prevention of certain disorders of the skin. Urol Cutaneous Rev 1946;50:106

19 Yamamoto A, Serizawa S, Ito M, Sato Y. Stratum corneum lipid abnormalities in atopic dermatitis. Arch Dermatol Res 1991; 283(4):219-223

20 Wertz PW, Miethke MC, Long SA, Strauss JS, Downing DT. The composition of the ceramides from human stratum corneum and from comedones. J Invest Dermatol 1985;84(5):410-412

21 Stiller MJ, Bartolone J, Stern R, et al. Topical 8\% glycolic acid and 8\% L-lactic acid creams for the treatment of photodamaged skin. A double-blind vehicle-controlled clinical trial. Arch Dermatol 1996;132(6):631-636

22 Yokota T, Matsumoto M, Sakamaki T, et al. Classification of sensitive skin and development of a treatment system appropriate for each group. IFSCC Mag. 2003;6:303-307

23 Pons-Guiraud A. Sensitive skin: a complex and multifactorial syndrome. J Cosmet Dermatol 2004;3(3):145-148

$24 \mathrm{Wu}$ KK. Salicylates and their spectrum of activity. Curr Med Chem 2007;6(4):278-292

25 Lin AN, Reimer RJ, Carter DM. Sulfur revisited. J Am Acad Dermatol 1988;18(3):553-558

26 Konaklieva MI, Plotkin BJ. Anti-inflammatory sulfur-containing agents with additional modes of action. Curr Med Chem 2007; 6(4):271-277

27 Plexion SCT. (sodium sulfacetamide $10 \%$ and sulfur 5\%) [package insert]. Scottsdale, AZ: Medicis, The Dermatology Company; 2001

28 Tarimci N, Sener S, Kilinç T. Topical sodium sulfacetamide/sulfur lotion. J Clin Pharm Ther 1997;22(4):301

29 Gupta AK, Nicol K. The use of sulfur in dermatology. J Drugs Dermatol 2004;3(4):427-431

30 Baumann LS. Less-known botanical cosmeceuticals. Dermatol Ther 2007;20(5):330-342

31 Talmadge J, Chavez J, Jacobs L, et al. Fractionation of Aloe vera L. inner gel, purification and molecular profiling of activity. Int Immunopharmacol 2004;4(14):1757-1773

32 Lee JK, Lee MK, Yun YP, et al. Acemannan purified from Aloe vera induces phenotypic and functional maturation of immature dendritic cells. Int Immunopharmacol 2001;1(7):1275-1284

33 Safayhi H, Sabieraj J, Sailer ER, Ammon HP. Chamazulene: an antioxidant-type inhibitor of leukotriene B4 formation. Planta Med 1994;60(5):410-413

34 Kwok BH, Koh B, Ndubuisi MI, Elofsson M, Crews CM. The antiinflammatory natural product parthenolide from the medicinal herb Feverfew directly binds to and inhibits IkappaB kinase. Chem Biol 2001;8(8):759-766
35 Martin K, Sur R, Liebel F, et al. Parthenolide-depleted Feverfew (Tanacetum parthenium) protects skin from UV irradiation and external aggression. Arch Dermatol Res 2008;300(2): 69-80

36 Ahn JY, Choi IS, Shim JY, et al. The immunomodulator ginsan induces resistance to experimental sepsis by inhibiting Toll-like receptor-mediated inflammatory signals. Eur J Immunol 2006; 36(1):37-45

37 Rhule A, Navarro S, Smith JR, Shepherd DM. Panax notoginseng attenuates LPS-induced pro-inflammatory mediators in RAW264.7 cells. J Ethnopharmacol 2006;106(1):121-128

38 Agarwal R, Wang ZY, Mukhtar H. Inhibition of mouse skin tumorinitiating activity of DMBA by chronic oral feeding of glycyrrhizin in drinking water. Nutr Cancer 1991;15(3-4):187-193

39 Barfod L, Kemp K, Hansen M, Kharazmi A. Chalcones from Chinese liquorice inhibit proliferation of $\mathrm{T}$ cells and production of cytokines. Int Immunopharmacol 2002;2(4):545-555

40 Sliva D. Ganoderma lucidum (Reishi) in cancer treatment. Integr Cancer Ther 2003;2(4):358-364

41 Xie JT, Wang CZ, Wicks S, et al. Ganoderma lucidum extract inhibits proliferation of SW 480 human colorectal cancer cells. Exp Oncol 2006;28(1):25-29

42 Dick LA. Colliodal emollient baths in pediatric dermatoses. Arch Pediatr 1958;75(12):506-508

43 Wallo W, Nebus J, Nystrand G. Agents with adjunctive potential in atopic dermatitis. J Am Acad Dermatol 2007;56(Suppl 2):AB70

44 Leverkus M, Yaar M, Eller MS, Tang EH, Gilchrest BA. Posttranscriptional regulation of UV induced TNF-alpha expression. J Invest Dermatol 1998;110(4):353-357

45 Stewart MS, Cameron GS, Pence BC. Antioxidant nutrients protect against UVB-induced oxidative damage to DNA of mouse keratinocytes in culture. J Invest Dermatol 1996;106(5):1086-1089

46 Rico MJ. Rising drug costs: the impact on dermatology. Skin Therapy Lett 2000;5(4):1-2, 5

47 Srimal RC, Dhawan BN. Pharmacology of diferuloyl methane (curcumin), a non-steroidal anti-inflammatory agent. J Pharm Pharmacol 1973;25(6):447-452

48 Woodley DT, Zelickson AS, Briggaman RA, et al. Treatment of photoaged skin with topical tretinoin increases epidermal-dermal anchoring fibrils. A preliminary report. JAMA 1990;263(22): 3057-3059

49 Fisher GJ, Datta SC, Talwar HS, et al. Molecular basis of suninduced premature skin ageing and retinoid antagonism. Nature 1996;379(6563):335-339

50 Kligman L, Kligman AM. Photoaging-retinoids, alpha hydroxy acids, and antioxidants. In: Gabard B, Elsner P, Surber C, Treffel P, eds. Dermatopharmacology of Topical Preparations. New York, NY: Springer; 2000:383

51 Kligman AM, Grove GL, Hirose R, Leyden JJ. Topical tretinoin for photoaged skin. J Am Acad Dermatol 1986;15(4 Pt 2): 836-859

52 Fisher GJ, Wang ZQ Datta SC, Varani J, Kang S, Voorhees JJ. Pathophysiology of premature skin aging induced by ultraviolet light. N Engl J Med 1997;337(20):1419-1428

53 Fisher GJ, Talwar HS, Lin J, Voorhees JJ. Molecular mechanisms of photoaging in human skin in vivo and their prevention by alltrans retinoic acid. Photochem Photobiol 1999;69(2):154-157

54 Kafi R, Kwak HS, Schumacher WE, et al. Improvement of naturally aged skin with vitamin A (retinol). Arch Dermatol 2007;143(5): 606-612

55 Kligman AM. The growing importance of topical retinoids in clinical dermatology: a retrospective and prospective analysis. J Am Acad Dermatol 1998;39(2 Pt 3):S2-S7

56 Weiss JS. Current options for the topical treatment of acne vulgaris. Pediatr Dermatol 1997;14(6):480-488

57 Environmental Working Group Report. Available at: http://www. ewg.org/2013sunscreen/fda-fails-consumers/. Accessed June 8, 2013 
58 Wang SQ Dusza SW, Lim HW. Safety of retinyl palmitate in sunscreens: a critical analysis. J Am Acad Dermatol 2010;63(5): 903-906

59 Duell EA, Kang S, Voorhees JJ. Unoccluded retinol penetrates human skin in vivo more effectively than unoccluded retinyl palmitate or retinoic acid. J Invest Dermatol 1997;109(3): 301-305

60 Kurlandsky SB, Xiao JH, Duell EA, Voorhees JJ, Fisher GJ. Biological activity of all-trans retinol requires metabolic conversion to alltrans retinoic acid and is mediated through activation of nuclear retinoid receptors in human keratinocytes. J Biol Chem 1994; 269(52):32821-32827

61 Draelos ZD. Therapeutic moisturizers. Dermatol Clin 2000;18(4): 597-607

62 Darr D, Combs S, Dunston S, Manning T, Pinnell S. Topical vitamin $C$ protects porcine skin from ultraviolet radiation-induced damage. Br J Dermatol 1992;127(3):247-253

63 Dunham WB, Zuckerkandl E, Reynolds R, et al. Effects of intake of L-ascorbic acid on the incidence of dermal neoplasms induced in mice by ultraviolet light. Proc Natl Acad Sci U S A 1982;79(23): 7532-7536

64 Weber C, Podda M, Rallis M, Thiele JJ, Traber MG, Packer L. Efficacy of topically applied tocopherols and tocotrienols in protection of murine skin from oxidative damage induced by UV-irradiation. Free Radic Biol Med 1997;22(5):761-769

65 Hoppe U, Bergemann J, Diembeck W, et al. Coenzyme Q10, a cutaneous antioxidant and energizer. Biofactors 1999;9(2-4): 371-378

66 Bagchi D, Bagchi M, Stohs SJ, et al. Free radicals and grape seed proanthocyanidin extract: importance in human health and disease prevention. Toxicology 2000;148(2-3):187-197

67 Bagchi D, Garg A, Krohn RL, Bagchi M, Tran MX, Stohs SJ. Oxygen free radical scavenging abilities of vitamins $C$ and $E$, and a grape seed proanthocyanidin extract in vitro. Res Commun Mol Pathol Pharmacol 1997;95(2):179-189

68 Aziz MH, Reagan-Shaw S, Wu J, Longley BJ, Ahmad N. Chemoprevention of skin cancer by grape constituent resveratrol: relevance to human disease? FASEB J 2005;19(9):11931195

69 Adhami VM, Afaq F, Ahmad N. Suppression of ultraviolet B exposure-mediated activation of NF-kappaB in normal human keratinocytes by resveratrol. Neoplasia 2003;5(1):74-82

70 Katiyar SK, Ahmad N, Mukhtar H. Green tea and skin. Arch Dermatol 2000;136(8):989-994

71 Vayalil PK, Mittal A, Hara Y, Elmets CA, Katiyar SK. Green tea polyphenols prevent ultraviolet light-induced oxidative damage and matrix metalloproteinases expression in mouse skin. J Invest Dermatol 2004;122(6):1480-1487

72 Arab L, Steck S. Lycopene and cardiovascular disease. Am J Clin Nutr 2000;71(6, Suppl)1691S-1695S, discussion 1696S-1697S

73 Baumann L. Botanical ingredients in cosmeceuticals. J Drugs Dermatol 2007;6(11):1084-1088

74 Farris P. Idebenone, green tea, and Coffeeberry extract: new and innovative antioxidants. Dermatol Ther 2007;20(5):322-329

75 Harman D. Aging: a theory based on free radical and radiation chemistry. J Gerontol 1956;11(3):298-300

76 Pelle E, Maes D, Padulo GA, Kim EK, Smith WP. An in vitro model to test relative antioxidant potential: ultraviolet-induced lipid peroxidation in liposomes. Arch Biochem Biophys 1990;283(2): 234-240

77 Ernster L, Dallner G. Biochemical, physiological and medical aspects of ubiquinone function. Biochim Biophys Acta 1995; 1271(1):195-204

78 Lee WC, Tsai TH. Preparation and characterization of liposomal coenzyme Q10 for in vivo topical application. Int J Pharm 2010; 395(1-2):78-83

79 Hsu S. Green tea and the skin. J Am Acad Dermatol 2005;52(6): 1049-1059
80 Wang ZY, Agarwal R, Bickers DR, Mukhtar H. Protection against ultraviolet $\mathrm{B}$ radiation-induced photocarcinogenesis in hairless mice by green tea polyphenols. Carcinogenesis 1991;12(8):1527-1530

81 Gensler HL, Timmermann BN, Valcic S, et al. Prevention of photocarcinogenesis by topical administration of pure epigallocatechin gallate isolated from green tea. Nutr Cancer 1996;26(3): 325-335

82 Khan WA, Wang ZY, Athar M, Bickers DR, Mukhtar H. Inhibition of the skin tumorigenicity of $(+/-)-7$ beta, 8 alpha-dihydroxy- 9 alpha,10 alpha-epoxy-7,8,9,10-tetrahydrobenzo[a]pyrene by tannic acid, green tea polyphenols and quercetin in Sencar mice. Cancer Lett 1988;42(1-2):7-12

83 Mittal A, Piyathilake C, Hara Y, Katiyar SK. Exceptionally high protection of photocarcinogenesis by topical application of (-)-epigallocatechin-3-gallate in hydrophilic cream in SKH-1 hairless mouse model: relationship to inhibition of UVB-induced global DNA hypomethylation. Neoplasia 2003;5(6):555-565

84 Elmets CA, Singh D, Tubesing K, Matsui M, Katiyar S, Mukhtar H. Cutaneous photoprotection from ultraviolet injury by green tea polyphenols. J Am Acad Dermatol 2001;44(3):425-432

85 Tzellos TG, Sardeli C, Lallas A, Papazisis G, Chourdakis M, Kouvelas D. Efficacy, safety and tolerability of green tea catechins in the treatment of external anogenital warts: a systematic review and meta-analysis. J Eur Acad Dermatol Venereol 2011;25(3): 345-353

86 Jang M, Cai L, Udeani GO, et al. Cancer chemopreventive activity of resveratrol, a natural product derived from grapes. Science 1997; 275(5297):218-220

87 Afaq F, Adhami VM, Ahmad N. Prevention of short-term ultraviolet $\mathrm{B}$ radiation-mediated damages by resveratrol in SKH-1 hairless mice. Toxicol Appl Pharmacol 2003;186(1):28-37

88 Ding XZ, Adrian TE. Resveratrol inhibits proliferation and induces apoptosis in human pancreatic cancer cells. Pancreas 2002;25(4): e71-e76

89 Athar M, Back JH, Tang X, et al. Resveratrol: a review of preclinical studies for human cancer prevention. Toxicol Appl Pharmacol 2007;224(3):274-283

90 Delmas D, Rébé C, Lacour S, et al. Resveratrol-induced apoptosis is associated with Fas redistribution in the rafts and the formation of a death-inducing signaling complex in colon cancer cells. J Biol Chem 2003;278(42):41482-41490

91 Reagan-Shaw S, Mukhtar H, Ahmad N. Resveratrol imparts photoprotection of normal cells and enhances the efficacy of radiation therapy in cancer cells. Photochem Photobiol 2008;84(2):415-421

92 Nichols JA, Katiyar SK. Skin photoprotection by natural polyphenols: anti-inflammatory, antioxidant and DNA repair mechanisms. Arch Dermatol Res 2010;302(2):71-83

93 Perricone NV. The photoprotective and anti-inflammatory effects of topical ascorbyl palmitate. J Geriatric Derm. 1993;1:5-10

94 Werninghaus $\mathrm{K}$. The role of antioxidants in reducing photodamage. In: Gilchrest B, ed. Photodamage. London, UK: Blackwell Science; 1995:249

95 Kameyama K, Sakai C, Kondoh S, et al. Inhibitory effect of magnesium L-ascorbyl-2-phosphate (VC-PMG) on melanogenesis in vitro and in vivo. J Am Acad Dermatol 1996;34(1):29-33

96 Ash K, Lord J, Zukowski M, McDaniel DH. Comparison of topical therapy for striae alba (20\% glycolic acid/0.05\% tretinoin versus $20 \%$ glycolic acid/10\% L-ascorbic acid). Dermatol Surg 1998;24(8): 849-856

97 Alster TS, West TB. Effect of topical vitamin C on postoperative carbon dioxide laser resurfacing erythema. Dermatol Surg 1998; 24(3):331-334

98 Nachbar F, Korting HC. The role of vitamin E in normal and damaged skin. J Mol Med (Berl) 1995;73(1):7-17

99 Baumann L. Minimizing the effect of scars. Miami Herald Web site. Available at: http://www.miamiherald.com/2012/11/13/ 3095098/minimizing-the-effect-of-scars.html\#. Accessed November 13, 2012 
100 Halliwell B. The antioxidant paradox. Lancet 2000;355(9210): $1179-1180$

101 Yuan XY, Liu W, Hao JC, Gu WJ, Zhao YS. Topical grape seed proanthocyandin extract reduces sunburn cells and mutant p53 positive epidermal cell formation, and prevents depletion of Langerhans cells in an acute sunburn model. Photomed Laser Surg 2012;30(1):20-25

102 American Academy of Dermatology Web site. Available at: http:// www.aad.org/media-resources/stats-and-facts/prevention-andcare/sunscreens. Accessed September 9, 2013

103 Lupo MP. Cosmeceutical peptides. Dermatol Surg 2005;31(7 Pt 2):832-836, discussion 836

104 Beer K, Kellner E, Beer J. Cosmeceuticals for rejuvenation. Facial Plast Surg 2009;25(5):285-289

105 Bauza E, Oberto G, Berghi A, Dal CF, Domloge N. Collagen-like peptide exhibits a remarkable antiwrinkle effect on the skin when topically applied: in vivo study. Int J Tissue React 2004; 26(3-4):105-111

106 Lupo MP. Cosmeceutical peptides. Dermatol Surg 2005;31(7 Pt 2):832-836, discussion 836

107 Lupo MP, Cole AL. Cosmeceutical peptides. Dermatol Ther 2007; 20(5):343-349

108 Katayama K, Armendariz-Borunda J, Raghow R, Kang AH, Seyer JM. A pentapeptide from type I procollagen promotes extracellular matrix production. J Biol Chem 1993;268(14):99419944

109 Robinson LR, Fitzgerald NC, Doughty DG, Dawes NC, Berge CA, Bissett DL. Topical palmitoyl pentapeptide provides improvement in photoaged human facial skin. Int J Cosmet Sci 2005;27(3): 155-160

110 Gorouhi F, Maibach HI. Role of topical peptides in preventing or treating aged skin. Int J Cosmet Sci 2009;31(5):327-345

111 Gorouhi F, Maibach HI. Role of topical peptides in preventing or treating aged skin. Int J Cosmet Sci 2009;31(5):327-345

112 Sim GS, Lee DH, Kim JH, et al. Black rice (Oryza sativa L. var. japonica) hydrolyzed peptides induce expression of hyaluronan synthase 2 gene in HaCaT keratinocytes. J Microbiol Biotechnol 2007; 17(2):271-279
113 Sim GS, Lee DH, Kim JH, et al. Black rice (Oryza sativa L. var. japonica) hydrolyzed peptides induce expression of hyaluronan synthase 2 gene in HaCaT keratinocytes. J Microbiol Biotechnol 2007;17(2):271-279

114 Gorouhi F, Maibach HI. Role of topical peptides in preventing or treating aged skin. Int J Cosmet Sci 2009;31(5):327-345

115 Padamwar MN, Pawar AP, Daithankar AV, Mahadik KR. Silk sericin as a moisturizer: an in vivo study. J Cosmet Dermatol 2005;4(4): 250-257

116 Gorouhi F, Maibach HI. Role of topical peptides in preventing or treating aged skin. Int J Cosmet Sci 2009;31(5):327-345

117 Guéniche A, Benyacoub J, Philippe D, et al. Lactobacillus paracasei CNCM I-2116 (ST11) inhibits substance P-induced skin inflammation and accelerates skin barrier function recovery in vitro. Eur J Dermatol 2010;20(6):731-737

118 Gorouhi F, Maibach HI. Role of topical peptides in preventing or treating aged skin. Int J Cosmet Sci 2009;31(5):327-345

119 Gorouhi F, Maibach HI. Role of topical peptides in preventing or treating aged skin. Int J Cosmet Sci 2009;31(5):327-345

120 Lupo MP, Cole AL. Cosmeceutical peptides. Dermatol Ther 2007; 20(5):343-349

121 Pickart L, Thaler MM. Tripeptide in human serum which prolongs survival of normal liver cells and stimulates growth in neoplastic liver. Nat New Biol 1973;243(124):85-87

122 Lupo MP, Cole AL. Cosmeceutical peptides. Dermatol Ther 2007; 20(5):343-349

123 Maquart FX, Pickart L, Laurent M, Gillery P, Monboisse JC, Borel JP. Stimulation of collagen synthesis in fibroblast cultures by the tripeptide-copper complex glycyl-L-histidyl-L-lysine-Cu2+. FEBS Lett 1988;238(2):343-346

124 Maquart FX, Bellon G, Chaqour B, et al. In vivo stimulation of connective tissue accumulation by the tripeptide-copper complex glycyl-L-histidyl-L-lysine-Cu2+ in rat experimental wounds. J Clin Invest 1993;92(5):2368-2376

125 Siméon A, Emonard H, Hornebeck W, Maquart FX. The tripeptidecopper complex glycyl-L-histidyl-L-lysine-Cu2+ stimulates matrix metalloproteinase-2 expression by fibroblast cultures. Life Sci 2000;67(18):2257-2265 